\title{
Sustainable control of tungiasis in rural Nigeria: a case for One Health
}

\author{
Jorg Heukelbach ${ }^{1}$, Liana Ariza', Rukayat Queen Adegbola², Uade Samuel Ugbomoiko² \\ ${ }^{1}$ Postgraduate Course in Public Health, School of Medicine, Federal University of Ceará, Fortaleza CE 60430-140, Brazil. \\ ${ }^{2}$ Parasitology Unit, Department of Zoology, University of Ilorin, Ilorin PMB 1515, Nigeria.
}

Correspondence to: Prof. Jorg Heukelbach, Postgraduate Course in Public Health, School of Medicine, Rua Prof. Costa Mendes 1608, 5 andar, Fortaleza CE 60430-140, Brazil. E-mail: heukelbach@web.de

How to cite this article: Heukelbach J, Ariza L, Adegbola RQ, Ugbomoiko US. Sustainable control of tungiasis in rural Nigeria: a case for One Health. One Health Implement Res 2021;1:4-13. https://dx.doi.org/10.20517/ohir.2021.01

Received: 21 Jan 2021 First Decision: 4 Mar 2021 Revised: 4 Mar 2021 Accepted: 16 Mar 2021 Available online: 17 Apr 2021

Academic Editor: Martin Pfeffer Copy Editor: Yue-Yue Zhang Production Editor: Yue-Yue Zhang

\begin{abstract}
Aim: To describe the impact and sustainability of an evidence-based intervention against tungiasis in a severely affected community in Lagos State, Nigeria.

Methods: We performed an intervention targeted at the control of tungiasis, and a cross-sectional follow-up study after one year. After 14 years, the community was revisited, and a rapid assessment was performed. Risk factors identified before the intervention included sandy floors inside houses, irregular use of footwear, and free-roaming pigs on the compound. In collaboration with community members and traditional leaders, the floors of the primary school and houses without concreted floor were sealed with concrete, free-roaming pigs were banned/confined to pigpens, and regular use of footwear and environmental hygiene, particularly consisting of cleaning the compound and streets from waste, were encouraged. We examined the participants for the presence of tungiasis on legs, feet, hands, and arms. Signs and symptoms were documented.
\end{abstract}

Results: In the baseline survey before intervention, 557 participants were included in the follow-up study after one year, 540 participants were included. The prevalence of tungiasis decreased from $45.2 \%$ to $21.3 \%$, and the total number of lesions from 3,111 to 617 (both $P<0.0001$ ). Severe symptoms and pathology (e.g., difficulty walking, deformation of toenails, loss of toenails, and bacterial superinfection) were reduced from high to negligible levels. After 14 years, there was no case with vital tungiasis lesions.

Conclusion: Long-term control of tungiasis is possible in heavily affected communities by considering an evidencebased One Health approach. Urbanization may have contributed to elimination of tungiasis after 14 years. 
Keywords: Tungiasis, One Health, implementation research, epidemiology, control, Africa

\section{INTRODUCTION}

The parasitic skin disease tungiasis - a neglected tropical disease - is highly endemic in many resource-poor communities in Africa, Latin America, the Caribbean, often causing high morbidities, particularly in underprivileged populations ${ }^{[1]}$. On the African continent, the disease is widespread, and a recent study suggested that 44 countries in sub-Saharan Africa provide suitable environmental characteristics for the occurrence of tungiasis ${ }^{[2]}$. Historical reports evidenced an extremely high burden of tungiasis throughout the African continent many years ago ${ }^{[3]}$, and recent studies show that numerable communities still suffer from severe infestations today, with a particularly high burden in schoolchildren ${ }^{[1,4-7]}$. In Nigeria, several historical and recent studies reported extremely high prevalences and demonstrated evidence that tungiasis is a major public health problem in the country ${ }^{[3,5,8-12]}$.

Considering the particular features and the life cycle of the ectoparasite Tunga penetrans, an integrated One Health Approach is pivotal to sustainably control the parasitosis in endemic communities ${ }^{[1,1,14]}$. There are domestic and sylvatic animal reservoirs; off-host stages develop at certain breeding sites in the community and even within houses. There is a strong link to poverty, poor living conditions, and hygiene. Additionally, individual behavior is crucial for the maintenance of transmission ${ }^{[15,16]}$.

Recent studies from sub-Saharan Africa and elsewhere have shown that - besides socioeconomic factors male gender, age $<15$ years and the older age groups, sandy floor inside houses, no regular use of footwear, and presence of animals on the compound are associated with higher prevalences and more severe morbidity ${ }^{[1,4,6,7,17,18]}$. In addition, the disease is usually not perceived as an important condition, neither by the populations affected, nor by decision makers and health personnel, and there are often no district or countrywide control programs ${ }^{[19-21]}$.

Here we present the results of evidence-based community implementation of control measures, based on prevalence and risk factor studies. The results show that prevalence and the parasite burden have been extremely reduced after one year. After 14 years, the community has undergone some urbanization changes, and no active tungiasis was found any more in the community.

\section{METHODS}

\section{Study area, population, and design}

The study area is a rural community in Lagos State, where tungiasis is highly endemic. The study area and design have been described in detail previously ${ }^{[2,23]}$. In brief, this is a resource-poor community about $50 \mathrm{~km}$ west of Lagos city. The population consists mainly of subsistence farmers and fishermen.

Epidemiological studies (i.e., baseline prevalence and morbidity assessment, animal prevalence study, and risk factor study) performed by the study group during the dry season (2006) have shown a high prevalence and morbidity of tungiasis, and identified several modifiable risk factors ${ }^{[22-24]}$. Domestic (especially freeroaming pigs and dogs) and sylvatic animals were commonly infected [Figure 1] ${ }^{[24]}$.

Guided by the observed risk factors and calculated population attributable fractions, we performed a community-based intervention, and after one year a systematic follow-up survey on prevalence and morbidity. In addition, 14 years after the baseline (2020), we revisited the community and performed a rapid assessment on the long-term sustainability of the intervention. 


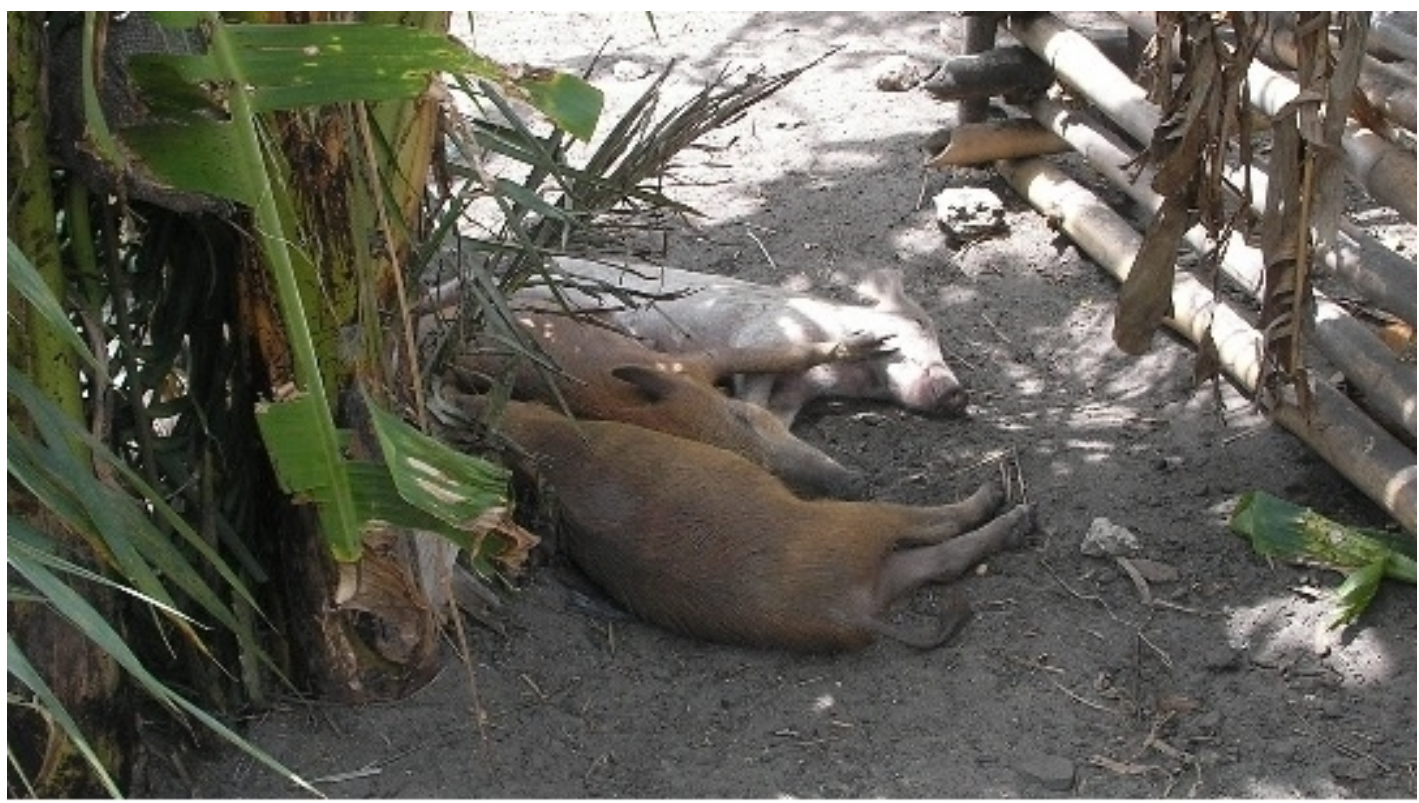

Figure 1. Free-roaming pigs resting on a compound in the community (before intervention).

The follow-up cross-sectional study was done during the high transmission season (dry season 2007). We examined the participants clinically for the presence of tungiasis on legs, feet, hands, and arms, using the baseline study diagnostic criteria ${ }^{[23]}$. Similarly, signs and symptoms associated with acute and chronic tungiasis were documented.

After 14 years (2020), the community was revisited, and a rapid assessment was performed to estimate the prevalence of tungiasis. We examined hands and legs of 300 individuals for the presence of active and inactive lesions, and noted occurrence of any severe tungiasis-related morbidity. The presence of pigs in the community was assessed. This assessment was done through personal observation by two of the authors (Ugbomoiko US \& Adegbola RQ) and non-formal key performants interviews, including the local Chief.

\section{Intervention}

The modifiable individual and community risk factors, identified as significantly associated in the baseline study and subsequently targeted at in the community-based intervention, included sand or clay inside the houses serving as possible flea breeding sites [population attributable fraction (PAF) $=73.7 \%$ ], no regular use of footwear $(\mathrm{PAF}=51.1 \%)$, and presence of free-roaming pigs on the compound ( $\mathrm{PAF}=37.9 \%$ ) [Figure 1] $]^{[22]}$. In particular, the community school was identified as a probable "hot spot", a high transmission site [Figure 2].

For the intervention, cement was provided for free to community members, and community participation was encouraged for upgrading houses by sealing sandy floors. In collaboration with community members and traditional leaders (Baales), the floors of the local primary school and of houses without concreted floor were provided with a concrete coating. Free-roaming pigs were banned, following an order of the traditional chief, and pig farming in general was discouraged. The few remaining pigs were confined to pigpens. The community members were encouraged to use footwear regularly, and to perform environmental hygiene, particularly consisting of cleaning regularly the compound and streets from waste. The compliance rate to the different interventions was assessed by semi-quantitative personal observations during and after the intervention. Community members were encouraged to perform tetanus vaccination, 


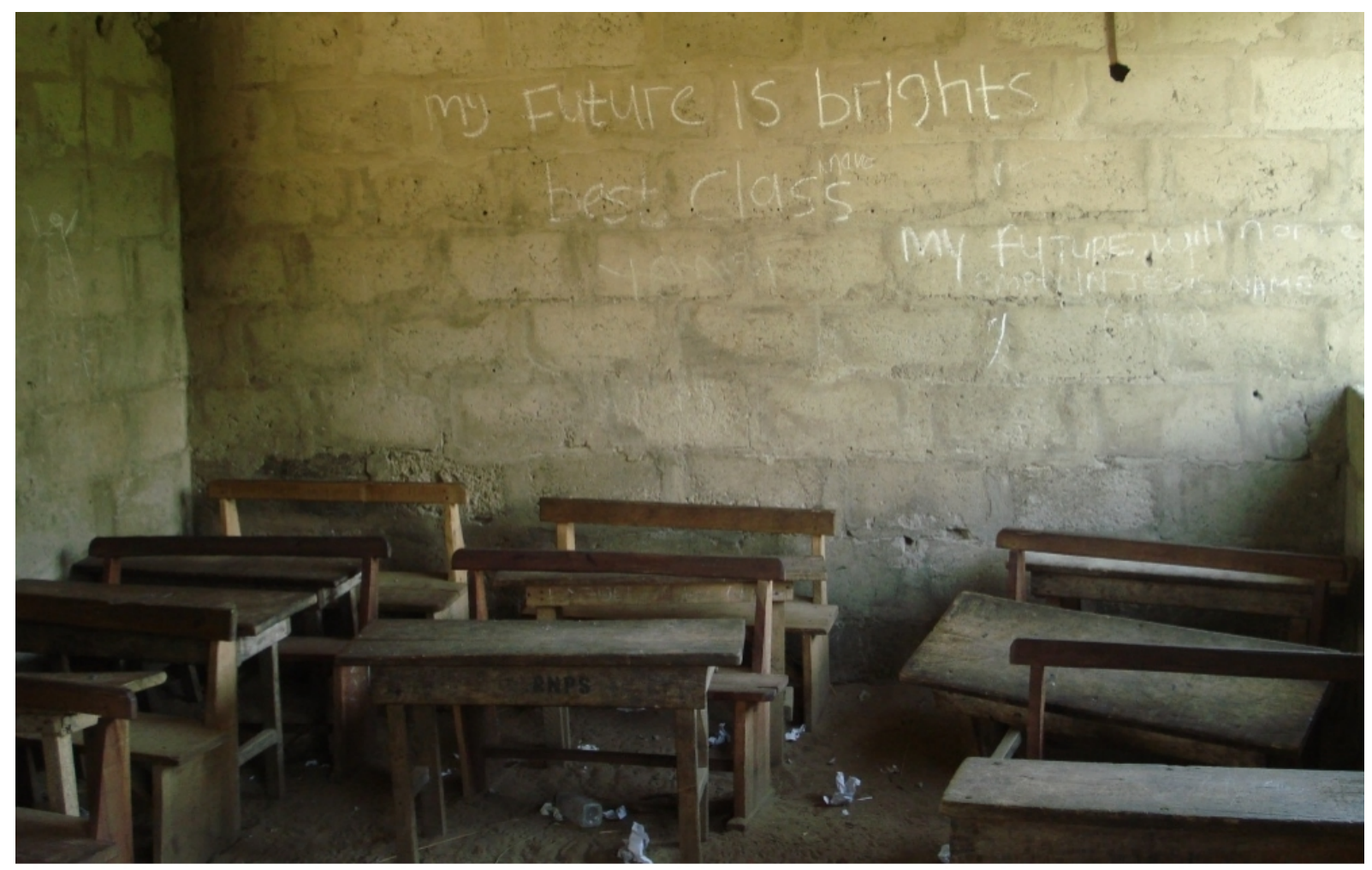

Figure 2. Local school with sandy floor, serving as breeding site for Tunga penetrans parasites (before intervention).

and referred to respective health services, especially in the case of severe infestation.

\section{Data analysis}

Data entry, checks for entry errors, and analyses were performed in line with the procedures described for the baseline survey ${ }^{[23]}$. We used the Epi Info software package (version 6.04d, Centers for Disease Control and Prevention, Atlanta, GA, USA). Ninety-five percent confidence intervals were calculated using the respective Epi Info modules. Data not distributed normally were presented as medians and interquartile ranges. The chi-squared test was used to determine the differences in relative frequencies. Differences in the medians between groups were assessed by the Wilcoxon test.

\section{RESULTS}

In the baseline study before intervention, a total of 557 participants had been included, while in the followup study after one year, 540 participants were included. Compliance to the specific intervention measures varied considerably [Table 1]. The banning of pigs in the community was well accepted, and the few remaining pigs in the village were confined on the family compounds; however, the regular use of footwear was only satisfactory. Environmental hygiene, aiming at the reduction of off-host breeding sites, showed fair compliance.

The overall prevalence of tungiasis reduced by half, from $45.2 \%$ to $21.3 \%$ at the one-year follow-up ( $P<$ 0.0001 , Table 2). The total number of lesions in the community was reduced from $>3,000$ at baseline to about one-fifth of that in the one-year follow-up [Figure 3]. In addition, the median number of fleas in the infected individuals was reduced considerably. A particularly high reduction of the number of embedded parasites was observed in those 60-year-old or older, where the median parasite load decreased from 41 to 
Table 1. Compliance rate of intervention measures in the community (semi-quantitative assessment)

\begin{tabular}{ll}
\hline Intervention & Compliance rate \\
\hline Banning free-roaming pigs in the community & Well accepted \\
Use of closed footwear & Satisfactory \\
Upgrade floor of houses with concrete & Satisfactory \\
Environmental hygiene & Fair \\
\hline
\end{tabular}

Table 2. Prevalence of tungiasis and parasite load, at baseline and one year after intervention, stratified by gender and age

\begin{tabular}{|c|c|c|c|c|c|c|}
\hline \multirow[b]{2}{*}{ Group } & \multicolumn{3}{|c|}{$\begin{array}{l}\text { Baseline }^{\star} \\
(n=557)\end{array}$} & \multicolumn{3}{|c|}{$\begin{array}{c}\text { Follow-up (1 year) } \\
\quad(n=540)\end{array}$} \\
\hline & $\begin{array}{l}\text { Positive/examined } \\
\text { (n) }\end{array}$ & $\begin{array}{l}\text { Prevalence } \\
(95 \% \mathrm{CI})\end{array}$ & $\begin{array}{l}\text { Median } \\
\text { number of } \\
\text { lesions (IQR) }\end{array}$ & $\begin{array}{l}\text { Positive/examined } \\
\text { (n) }\end{array}$ & $\begin{array}{l}\text { Prevalence } \\
(95 \% \mathrm{Cl})\end{array}$ & $\begin{array}{l}\text { Median } \\
\text { number of } \\
\text { lesions } \\
\text { (IQR) }\end{array}$ \\
\hline \multicolumn{7}{|l|}{ Gender } \\
\hline Male & $141 / 299$ & $47.2 \%(41.4-53.0)$ & $7(3-19)$ & $71 / 291$ & $24.4 \%(19.6-29.8)$ & $4(2-7)$ \\
\hline Female & $111 / 258$ & $43.0 \%(36.9-49.3)$ & $4(2-13)$ & $44 / 249$ & $17.7 \%(13.1-23.0)$ & $5(2-8)$ \\
\hline \multicolumn{7}{|l|}{ Age group } \\
\hline $0-4$ years & $19 / 49$ & $38.8 \%(25.2-35.8)$ & $4(2-8)$ & $8 / 49$ & $16.3 \%(7.3-29.7)$ & $3(2.5-6)$ \\
\hline $5-9$ years & $102 / 159$ & $64.2 \%(56.2-71.6)$ & $5(2-11)$ & $54 / 158$ & $34.2 \%(26.8-42.1)$ & $4(2-8)$ \\
\hline $10-14$ years & $77 / 121$ & $63.6 \%(54.4-72.2)$ & $9(2-19)$ & $31 / 116$ & $26.7 \%(18.9-35.7)$ & $5(2-9)$ \\
\hline $15-19$ years & $9 / 71$ & $12.7 \%(6.0-22.7)$ & $4(4-18)$ & $4 / 72$ & $5.6 \%(1.5-12.6)$ & $2(2-2)$ \\
\hline 20-39 years & $13 / 82$ & $15.9 \%(8.7-25.6)$ & $8(4-13)$ & $5 / 78$ & $6.4 \%(2.1-14.3)$ & $2(2-2)$ \\
\hline 40-59 years & $23 / 58$ & $39.7 \%(27.0-53.4)$ & $9(3-17)$ & $9 / 53$ & $17.0 \%(8.1-29.8)$ & $5(4-17)$ \\
\hline 60 years & $9 / 17$ & $52.9 \%(27.8-77.0)$ & $41(6-57)$ & $4 / 14$ & $28.6 \%(8.4-58.1)$ & $7.5(3.5-11)$ \\
\hline Total & $252 / 557$ & $45.2 \%$ & $6(3-16)$ & $115 / 540$ & $21.3 \%(17.9-25.0)$ & $5(2-8)$ \\
\hline
\end{tabular}

${ }^{\star}$ Baseline data previously published in ${ }^{[23]}$. Cl: Confidence interval; IQR: interquartile range.

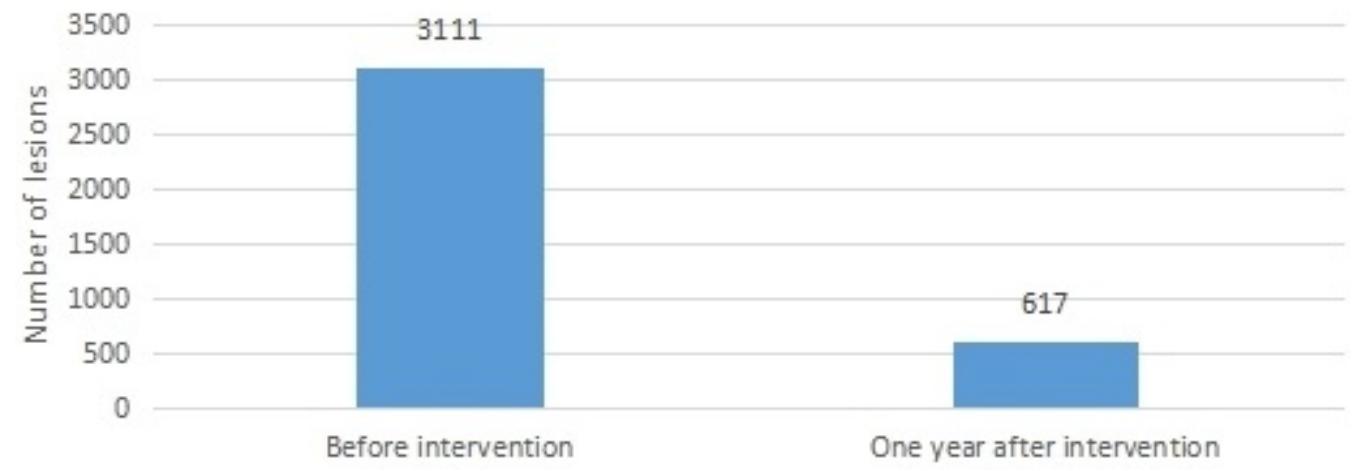

Figure 3. Total number of tungiasis lesions (penetrated parasites) in the community members at baseline and one year after intervention.

7.5 embedded parasites $(P<0.001$, Table 2$)$.

Signs and symptoms in patients with tungiasis are presented in Figure 4. The pathognomonic clinical signs and symptoms associated with tungiasis (such as itching, erythema, desquamation of skin, and edema) persisted at similarly high frequencies after one year, but severe symptoms and pathology (such as difficulty walking, deformation of toenails, loss of toenails, and bacterial superinfection/pustules) were reduced from 


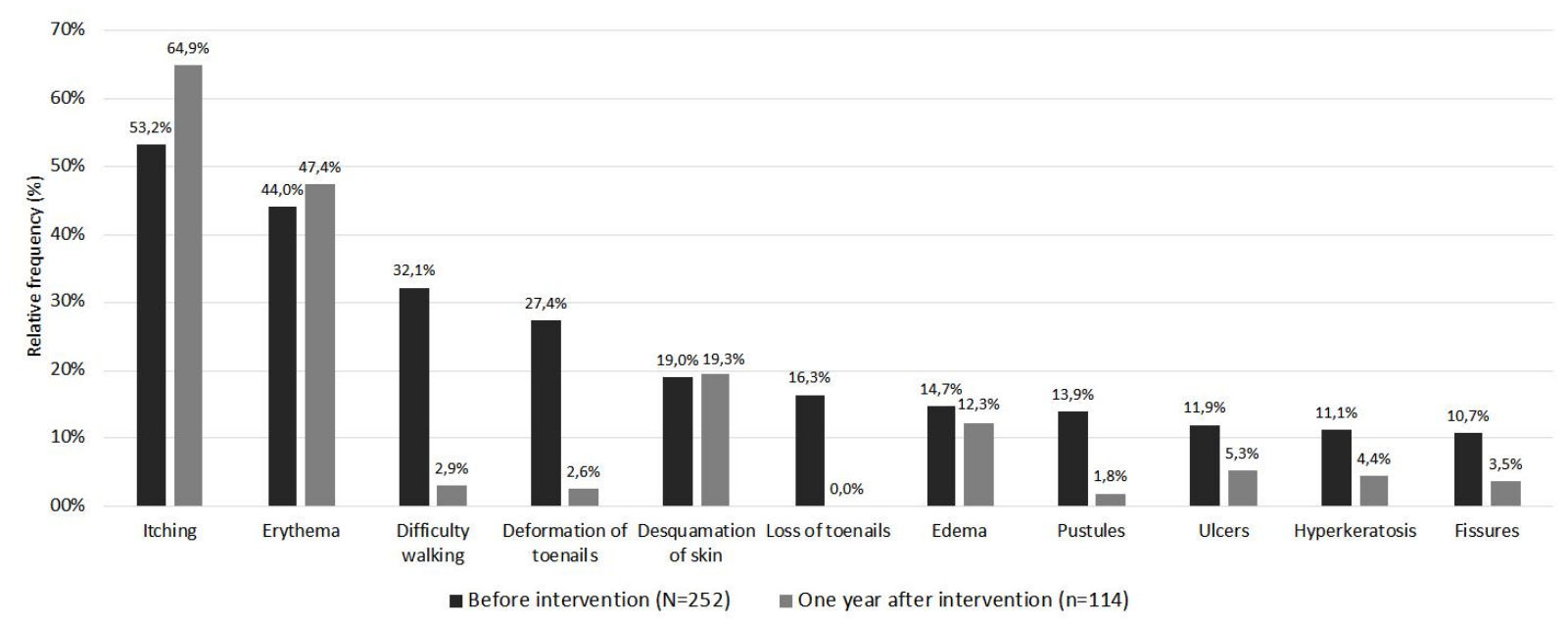

Figure 4. Tungiasis-associated signs and symptoms before $(n=252)$ and one year after $(n=114)$ intervention in patients with tungiasis.

high to negligible levels.

After 14 years, urbanization has progressed in the community. Several houses were upgraded, and roads in the community which used to be sand tracks, are now accessible unpaved dirt roads. During this second follow-up no severe pathologies and symptoms at all were observed, and the community members and leaders denied any such cases. Evidence of avital lesions were found in 16/300 (5.3\%) examined individuals, but there was no individual with vital tungiasis lesions. The intervention was well remembered by the chief and community members, as the positive effects were still being perceived. Free-roaming pigs were still controlled in the community. The community expressed their extreme gratitude regarding the sustainable control of tungiasis throughout these years. In fact, the successful implementation of the intervention measures had caused a practice change in the region, with other communities adopting similar control measures.

\section{DISCUSSION}

This study shows that an interdisciplinary evidence-based approach has been effective for the control of tungiasis in an extremely affected rural community. Prevalence of tungiasis decreased sustainably, from $45 \%$ to $21 \%$ after one year, and the total number of lesions in the community, which is also an indicator of transmissions dynamics, was reduced from more than 3000 to about 600 , as a consequence of the lower individual parasite load.

In tungiasis-affected individuals, the parasite load is known to be linked to morbidity ${ }^{[25]}$. Consequently, severe signs and symptoms were reduced to low levels. Before intervention, about one third of infested individuals had complained of difficulty walking. This was reduced to three cases after one year. Similarly, clinical bacterial superinfections were observed in about one-seventh of cases, and virtually disappeared after the intervention. Itching, erythema, edema, and desquamation of skin still occurred in individuals with new tungiasis lesions, as these signs and symptoms are typical and very common, also in the presence of single lesions ${ }^{[25,26]}$. 
Of particular interest is the spillover effect to other communities in the region - the success story has spread rapidly between communities, and local leaders adopted the measures for their populations. This practice change may be a driver and motivation for policy makers at the state and national levels to implement systematic control programs at low cost. However, so far there are no state and national tungiasis control programs in Nigeria, and the described intervention relied solely on collaboration with community leaders and the community. The cooperation with local communities has been detected as a key driver for effective tungiasis control also in Kenyan communities, where a local NGO intensively cooperated with local communities and policy makers ${ }^{[14]}$.

Intervention programs usually rely on individual treatment of severely affected individuals, and on schoolbased mass treatments. In rural Madagascar, the regular application of a plant-based repellent reduced the attack rate to zero, confirming previous studies from Brazil on the efficacy of this repellent ${ }^{[27,28]}$. Another treatment option with proven efficacy is the topical application of the silicon oil dimeticone, which has been marketed also as treatment against head lice, being considered as very safe ${ }^{[29-32]}$. Due to limited funding, and the absence of any health infrastructure in the Nigerian community, we adopted the multi-disciplinary approach on the community level, though without any provision of individual treatment, nor insecticide surface spraying. A Brazilian intervention in a fishing community relied on individual treatment and insecticide spraying of premises ${ }^{[33]}$. While effective control was achieved as compared to a control community without intervention, the effect did not last for a long time ${ }^{[33]}$. In the Kenyan community-based intervention, tungiasis was successfully controlled based on treatment with a natural product made from on neem and coconut oil, spraying floors with neem solution, and distribution of closed shoes ${ }^{[14]}$.

The long-lasting success in our study was achieved as a result of intensive commitment of the community leaders, and mobilization of the community. While this worked out very well for some intervention measures, others - such as environmental hygiene measures aimed at the reduction of organic waste in the community and subsequently reduced breeding sites for the parasite - did not reveal the expected participation of the community members. The reasons may lie in cultural habits, and the fact that in the community no regular waste collection is performed. The use of shoes was observed as being only satisfactory, and may not have been the principal driver for the reduction of attack rates. In rural Madagascar, a study has shown that the propagation of use of closed shoes decreased only marginally the attack rate ${ }^{[34]}$.

While tungiasis control can be seen as a paradigmatic example for the adoption of the One Health approach, it should be kept in mind that poverty-related diseases are linked to each other. As access to the affected populations is a key pillar to effective control, tungiasis would ideally be integrated into existing control programs for other diseases (such as soil-transmitted helminths, malaria, and onchocerciasis), WASH, and school-based interventions. Additional benefits of tungiasis control are to be expected, depending on the particular settings. For example, tungiasis lesions have been considered as an entry point for anaerobic bacteria, and the incidence of tetanus may be reduced in high risk areas ${ }^{[35-37]}$. Applying a repellent to the feet may have positive effects on other diseases such as hookworm infections and cutaneous larva migrans, as helminth larvae may be repelled from penetrating the skin. Topical compounds such as dimeticones that are distributed, may also be used in the community for treatment of pediculosis. Freeranging pigs are considered a major risk factor for human cysticercosis, and control of rats as another important animal reservoir for tungiasis will reduce the occurrence of leptospirosis or rodent-borne viruses such as Lassa virus ${ }^{[38,39]}$. However, as vividly described by a former Minister of Health, many politicians and health professionals maintain in their silos, and the implementation of One Health may be a challenge in political practice ${ }^{[40]}$. 
We are aware that the situation and necessary approach may differ in other communities, with different cultural habits, differing animal reservoirs and other religious backgrounds. For example, it is not expected that pigs would play a major role in communities where the Islamic religion prevails; and in urban settings, dogs and rats usually would play a more important role, as compared to pigs and sylvatic animals in rural settings ${ }^{[24,41,42]}$. We have focused our intervention on the pig animal reservoir, as previous studies in the community on the animal reservoir and risk factors showed that pigs harbored more than $80 \%$ of lesions in animals, and these animals were by far the most important risk factor ( $\mathrm{OR}=19.7$ for the presence of pigs, as compared to $\mathrm{OR}=1.8$ for the presence of dogs on the compound $)^{[2,24]}$.

Our study is subject to limitations. As the intervention was performed without any control community, the results should be interpreted with care. However, we did not observe any considerable changes in the community after one year. After 14 years, the community has been increasingly urbanized, and the additional benefit as compared to the first follow-up after one year may largely be attributed to the better living conditions, in addition to the reduced animal reservoir in the community, especially pigs.

Our study shows that sustainable intervention is feasible for a long period, based on the One Health approach. Policy makers and health professionals will have to create synergies between communities and regions and develop local, national, and regional control programs to reduce the severe burden caused by tungiasis, with the aim to eliminate tungiasis as a public health problem from the continent. The recent inclusion of tungiasis and other skin diseases in WHO's list of neglected tropical diseases has been an important milestone in advocating this issue to a wider audience.

\section{DECLARATIONS}

\section{Acknowledgments}

We are indebted to the community members as well as the Baales of Erekiti and Ajido Erekiti communities for supporting the study.

\section{Authors' contributions}

Made substantial contributions to conception and design of the study and performed data acquisition, analysis and interpretation, and wrote the manuscript: Heukelbach J, Ariza L, Adegbola RQ, Ugbomoiko US

\section{Availability of data and materials}

Data will be made by authors upon reasonable request.

\section{Financial support and sponsorship}

Liana Ariza received a PhD scholarship from Coordenação de Aperfeiçoamento de Pessoal de Nivel SuperiorCAPES (Brazil). The study was supported in part by a PROÁFRICA grant from the Conselho Nacional de Desenvolvimento Cientifico e Tecnológico (CNPq/Brazil). Jorg Heukelbach is research fellow from CNPq.

\section{Conflicts of interest}

All authors declared that there are no conflicts of interest.

\section{Ethical approval and consent to participate}

The Ethical Committee of the Badagry Local Government Public Health Board, which is composed of medical and administrative personnel, approved the study. Before the study, the objectives and the study protocol were explained during meetings with the community leaders of Erekiti and a representative of the Ethical Committee. The community leaders also approved the study. In accordance with local requirements, consent was obtained after explaining the objectives from all study participants, or in case of minors, from 
their caretakers. The statement was translated into the local language by our interpreter. The consent was witnessed by a person not involved in the study (usually a community representative). The participants signed, by thumbprinting, a spreadsheet containing details of their biodata.

\section{Consent for publication}

Not applicable.

\section{Copyright}

(c) The Author(s) 2021.

\section{REFERENCES}

1. Obebe OO, Aluko OO. Epidemiology of tungiasis in sub-saharan Africa: a systematic review and meta-analysis. Pathog Glob Health 2020;114:360-9. DOI PubMed PMC

2. Deka MA. Mapping the geographic distribution of tungiasis in Sub-Saharan Africa. Trop Med Infect Dis 2020;5:122. DOI PubMed PMC

3. Heukelbach J, Ugbomoiko US. Tungiasis in the past and present: a dire need for intervention. Nig J Parasitol 2007;28:1-5. DOI

4. Elson L, Wiese S, Feldmeier H, Fillinger U. Prevalence, intensity and risk factors of tungiasis in Kilifi County, Kenya II: Results from a school-based observational study. PLoS Negl Trop Dis 2019;13:e0007326. DOI PubMed PMC

5. Ugbomoiko US, Ariza L, Babamale AO, Heukelbach J. Prevalence and clinical aspects of tungiasis in south-west Nigerian schoolchildren. Trop Doct 2017;47:34-8. DOI PubMed

6. Nsanzimana J, Karanja S, Kayongo M, et al. Factors associated with tungiasis among primary school children: a cross-sectional study in a rural district in Rwanda. BMC Public Health 2019;19:1192. DOI PubMed PMC

7. Girma M, Astatkie A, Asnake S. Prevalence and risk factors of tungiasis among children of Wensho district, southern Ethiopia. BMC Inf Dis 2018;18:456. DOI PubMed PMC

8. Nte AR, Eke FU. Jigger infestation in children in a rural area of Rivers State of Nigeria. West Afr J Med 1995;14:56-8. PubMed

9. Arene FO. The prevalence of sand flea (Tunga penetrans) among primary and post-primary school pupils in Choba area of the Niger Delta. Public Health 1984;98:282-3. DOI PubMed

10. Ade-Serrano MA, Ejezie GC. Prevalence of tungiasis in Oto-Ijanikin village, Badagry, Lagos State, Nigeria. AnnTrop Med Parasitol 1981;75:471-2. DOI PubMed

11. Ejezie GC. The parasitic diseases of school children in Lagos State, Nigeria. Acta Tropica 1981;38:79-84. PubMed

12. Atunrase JO, Awobodu CA, Fawole CA, Rosanwo PO. Some observations on tungiasis in Yorubaland, Western Nigeria. West Afr J Med 1952;3:181-2.

13. Heukelbach J. One Health \& Implementation Research: Improving Health for All. One Health Implement Res 2020;1:1-3. DOI

14. Elson L, Wright K, Swift J, Feldmeier H. Control of tungiasis in absence of a roadmap: grassroots and global approaches. Trop Med Infect Dis 2017;2:33. DOI PubMed PMC

15. Feldmeier H, Heukelbach J, Ugbomoiko US, et al. Tungiasis-a neglected disease with many challenges for global public health. PLoS Negl Trop Dis 2014;8:e3133. DOI PubMed PMC

16. Heukelbach J, Mencke N, Feldmeier H. Editorial: Cutaneous larva migrans and tungiasis: the challenge to control zoonotic ectoparasitoses associated with poverty. Trop Med IntHealth 2002;7:907-10. DOI PubMed

17. Wafula ST, Ssemugabo C, Namuhani N, Musoke D, Ssempebwa J, Halage AA. Prevalence and risk factors associated with tungiasis in Mayuge district, Eastern Uganda. Pan Afr Med J 2016;24:77. DOI PubMed PMC

18. Muehlen M, Feldmeier H, Wilcke T, Winter B, Heukelbach J. Identifying risk factors for tungiasis and heavy infestation in a resourcepoor community in Northeast Brazil. Trans R Soc Trop Med Hyg 2006;100:371-80. DOI PubMed

19. Heukelbach J, Feldmeier H. Ectoparasites-the underestimated realm. Lancet 2004;363:889-91. DOI PubMed

20. Heukelbach J, de Oliveira FA, Hesse G, Feldmeier H. Tungiasis: a neglected health problem of poor communities. Trop Med Int Health 2001;6:267-72. DOI PubMed

21. Winter B, Oliveira FA, Wilcke T, Heukelbach J, Feldmeier H. Tungiasis-related knowledge and treatment practices in two endemic communities in northeast Brazil. J Infect Dev Ctries 2009;3:458-66. DOI PubMed

22. Ugbomoiko US, Ariza L, Ofoezie IE, Heukelbach J. Risk factors for tungiasis in Nigeria: identification of targets for effective intervention. PLoS Negl Trop Dis 2007;1:e87. DOI PubMed PMC

23. Ugbomoiko US, Ofoezie IE, Heukelbach J. Tungiasis: high prevalence, parasite load, and morbidity in a rural community in Lagos State, Nigeria. Int J Dermatol 2007;46:475-81. DOI PubMed

24. Ugbomoiko US, Ariza L, Heukelbach J. Pigs are the most important animal reservoir for Tunga penetrans (jigger flea) in rural Nigeria. Trop Doct 2008;38:226-7. DOI PubMed

25. Kehr JD, Heukelbach J, Mehlhorn H, Feldmeier H. Morbidity assessment in sand flea disease (tungiasis). Parasitol Res 2007;100:41321. DOI PubMed

26. Eisele M, Heukelbach J, Van Marck E, et al. Investigations on the biology, epidemiology, pathology and control of Tunga penetrans in Brazil: I. Natural history of tungiasis in man. Parasitol Res 2003;90:87-99. DOI PubMed 
27. Buckendahl J, Heukelbach J, Ariza L, Kehr JD, Seidenschwang M, Feldmeier H. Control of tungiasis through intermittent application of a plant-based repellent: an intervention study in a resource-poor community in Brazil. PLoS Negl Trop Dis 2010;4:e879. DOI PubMed PMC

28. Feldmeier H, Kehr JD, Heukelbach J. A plant-based repellent protects against Tunga penetrans infestation and sand flea disease. Acta Trop 2006;99:126-36. DOI PubMed

29. Miller H, Trujillo-Trujillo J, Mutebi F, Feldmeier H. Efficacy and safety of dimeticones in the treatment of epidermal parasitic skin diseases with special emphasis on tungiasis: an evidence-based critical review. Braz J Infect Dis 2020;24:170-7. DOI PubMed

30. Nordin P, Thielecke M, Ngomi N, Mudanga GM, Krantz I, Feldmeier H. Treatment of tungiasis with a two-component dimeticone: a comparison between moistening the whole foot and directly targeting the embedded sand fleas. Trop Med Health 2017;45:6. DOI PubMed PMC

31. Thielecke M, Nordin P, Ngomi N, Feldmeier H. Treatment of Tungiasis with dimeticone: a proof-of-principle study in rural Kenya. PLoS Negl Trop Dis 2014;8:e3058. DOI PubMed PMC

32. Heukelbach J, Pilger D, Oliveira FA, Khakban A, Ariza L, Feldmeier H. A highly efficacious pediculicide based on dimeticone: randomized observer blinded comparative trial. BMC Inf Dis 2008;8:115. DOI PubMed PMC

33. Pilger D, Schwalfenberg S, Heukelbach J, et al. Controlling tungiasis in an impoverished community: an intervention study. PLoS Negl Trop Dis 2008;2:e324. DOI PubMed PMC

34. Thielecke M, Raharimanga V, Rogier C, Stauss-Grabo M, Richard V, Feldmeier H. Prevention of tungiasis and tungiasis-associated morbidity using the plant-based repellent Zanzarin: a randomized, controlled field study in rural Madagascar. PLoS Negl Trop Dis 2013;7:e2426. DOI PubMed PMC

35. Feldmeier H, Heukelbach J, Eisele M, Sousa AQ, Barbosa LM, Carvalho CB. Bacterial superinfection in human tungiasis. Trop Med Int Health 2002;7:559-64. DOI PubMed

36. La tungose et le tétanos au C.H.U. de Brazzaville [Tungiasis and tetanus at the University Hospital Center in Brazzaville]. Dakar Med 1989;34:44-8. (in French). PubMed

37. Tonge BL. Tetanus from chigger flea sores. J Trop Pediatr 1989;35:94. DOI PubMed

38. Mwabonimana MF, Inyagwa CM, Bebe BO, Shakala EK, King'ori AM. Porcine cysticercosis control in Western Kenya: the interlink of management practices in pig farms and meat inspection practice at slaughter slabs. Vet Med Int 2020;2020:7935656. DOI PubMed PMC

39. Boey K, Shiokawa K, Rajeev S. Leptospira infection in rats: A literature review of global prevalence and distribution. PLoS Negl Trop Dis 2019;13:e0007499. DOI PubMed PMC

40. Uribe AG. My experience with "one health": from realism to optimism. One Health Implement Res. Forthcoming 2021.

41. Mutebi F, Krucken J, Feldmeier H, et al. Animal reservoirs of zoonotic tungiasis in endemic rural villages of Uganda. PLoS Negl Trop Dis 2015;9:e0004126. DOI PubMed PMC

42. Heukelbach J, Costa AM, Wilcke T, Mencke N, Feldmeier H. The animal reservoir of Tunga penetrans in severely affected communities of north-east Brazil. Med Vet Entomol 2004;18:329-35. DOI PubMed 